\title{
Prospective three-year follow up of a cohort study of 240 patients with chronic facial pain
}

\author{
A M AGIUS ${ }^{1}, \mathrm{~N} \mathrm{~S} \mathrm{JONES}^{2}, \mathrm{R}^{\mathrm{MUSCAT}}{ }^{3}$ \\ ${ }^{1}$ The Medical School, University of Malta, Msida, Malta, ${ }^{2}$ Department of Otolaryngology, University of \\ Nottingham, UK, and ${ }^{3}$ Department of Physiology and Biochemistry, University of Malta, Msida, Malta
}

\begin{abstract}
Background: Patients often present with facial pain ascribed to sinusitis, despite normal nasal endoscopy and sinus computed tomography. Facial pain is increasingly recognised to be of neurological origin.

Method: A cohort of 240 patients with chronic facial pain was followed up for 36 months at an otolaryngological practice in Malta. The types of facial pain were classified according to International Headache Classification criteria. The body mass index, occupation and educational level of patients were compared with the general population.

Results: Tension-type mid-facial pain and facial migraine without aura were the most common types of chronic facial pain. The sites of pain, symptoms, treatment and outcomes for these principal pain types are discussed. Patients with mid-facial pain were treated with low-dose amitriptyline for eight weeks. After three years, nearly half of the patients were symptom free, and in a third the pain changed from being chronic to being episodic. The treatment of patients with facial migraine was more varied but the length of time until recurrence of pain was similar.

Conclusion: The most effective long-term treatments for tension-type mid-facial pain and facial migraine were low-dose amitriptyline and low-dose amitriptyline and triptans, respectively.
\end{abstract}

Key words: Cohort Studies; Facial Pain; Tension-Type Headache; Migraine

\section{Introduction}

The study was set in a community-based otolaryngology practice in Malta. Retrospective records of 7476 patients presenting at a rhinology clinic showed that 25 per cent had significant facial pain. A cohort of 240 patients who satisfied the criteria for chronic facial pain was followed for 3 years in an attempt to classify the types of facial pain according to International Headache Society criteria ${ }^{1}$ and to report on long-term patient outcome. The study aimed to identify clinical patterns in these patients that could help the otolaryngologist distinguish between the main categories of chronic facial pain. The body mass index (BMI), occupation and educational level of this cohort were compared to those in the general population.

A recent study of 305 Maltese patients who satisfied the 1997 American Academy Taskforce clinical criteria for chronic rhinosinusitis identified facial pain as the commonest principal presenting symptom. However, 60 per cent of these patients had normal sinus computed tomography (CT) scans. 'Sinusitis' may therefore not have been an appropriate diagnosis in spite of chronic facial pain. ${ }^{3}$ The European Position Paper of 2007 published revised diagnostic criteria for rhinosinusitis that included correlation of $\mathrm{CT}$ with nasal endoscopic findings. ${ }^{4}$ The 2012 update contained a section on facial pain as this may present under the guise of chronic rhinosinusitis. ${ }^{5}$

Patients presenting with symptoms of rhinosinusitis, but with normal sinus CT and nasal endoscopy, have responded to medical treatment for neurological diagnoses. ${ }^{6}$ Jones described mid-facial segmental pain as a tension-type pain of neurological origin, pressing or aching in quality, with a bilateral distribution involving the nasion, peri-orbital regions, cheeks or paranasal areas. $^{7}$ Mid-facial segmental pain involves the frontal, parietal and occipital regions and is associated with tension-type headaches. ${ }^{8}$

Tension-type pain is thought to be due to sensitisation of second order neurons at the trigeminal nucleus subcaudalis, which is the facial equivalent of the dorsal horn of the spinal cord (Figure 1). ${ }^{9}$ Face, head and neck afferents converge onto the subnucleus caudalis. This convergence explains why headache and neck ache frequently accompany tension-type facial pain. ${ }^{10,11}$ Convergence may also explain why autonomic nasal symptoms frequently accompany chronic facial pain.

Jones suggested low-dose amitriptyline as an effective treatment for mid-facial pain. ${ }^{7}$ Tricyclic 


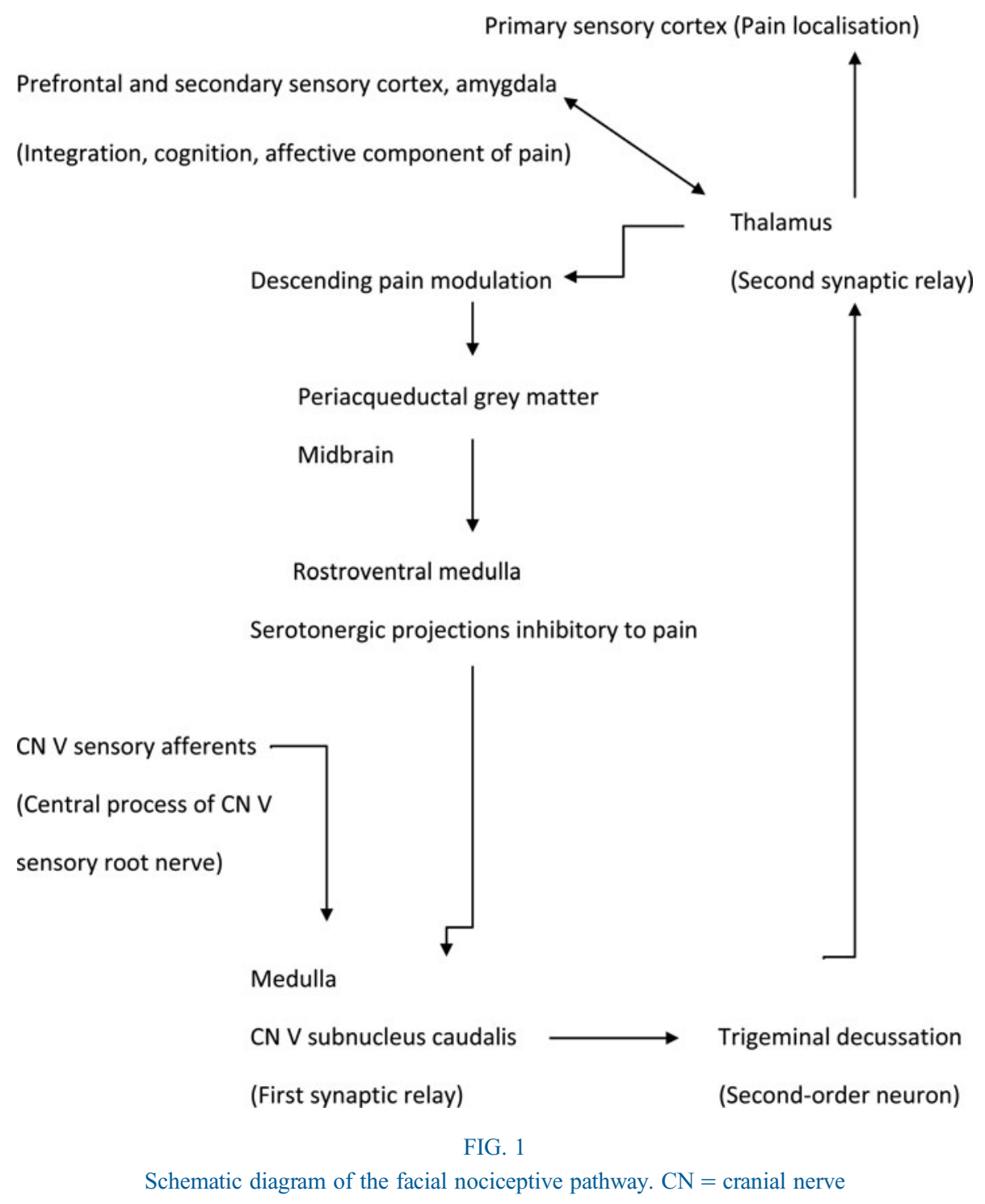

antidepressants are known to be effective in the prophylaxis of tension-type headache and are thought to reduce the sensitivity of second order neurons at the level of the spinal cord. ${ }^{12}$

In chronic tension-type headache, as defined by the International Headache Society classification 2.3, patients have at least 15 days per month with headache along with the characteristics detailed in Table I. ${ }^{1}$ The criteria for chronic mid-facial pain were extrapolated from these criteria.

Migraine is a common episodic disorder of the central nervous system, affecting 10 to 15 per cent of the population. It is more prevalent in women, with a female-to-male ratio of $3: 1$, and peaks at the fourth to fifth decade of life. ${ }^{13-15}$ Migraine causes a unilateral throbbing-type headache with photophobia, phonophobia, nausea and vomiting. The headache sometimes spreads to the face. In migraine with aura, the pain is preceded by neurological symptoms such as visual disturbances or numbness. Of 100 patients who referred themselves for 'sinus headache', up to 52 per cent were classified as having migraine without aura. ${ }^{16}$
Facial migraine without aura may be easily misdiagnosed as 'sinusitis' because autonomic nasal symptoms may be present. ${ }^{17}$

The International Headache Society defines chronic migraine as over 15 days per month with headache with the characteristics described in Table II.

\section{TABLE I}

\section{DIAGNOSTIC CRITERIA FOR CHRONIC TENSION-TYPE} HEADACHE $^{1}$

A Headache occurring $\geq 15$ days per month on average for $>3$ months, \& fulfilling criteria B-D

B Headache lasts for hours or is continuous

C Headache has $\geq 2$ of following characteristics:

- Bilateral location

- Pressing or tightening (non-pulsating) quality

- Mild or moderate intensity

- Not aggravated by routine physical activity (e.g. walking or climbing stairs)

D Both of following:

- No more than 1 of: photophobia, phonophobia or mild nausea

- Neither moderate-to-severe nausea nor vomiting

E Not attributed to another disorder 


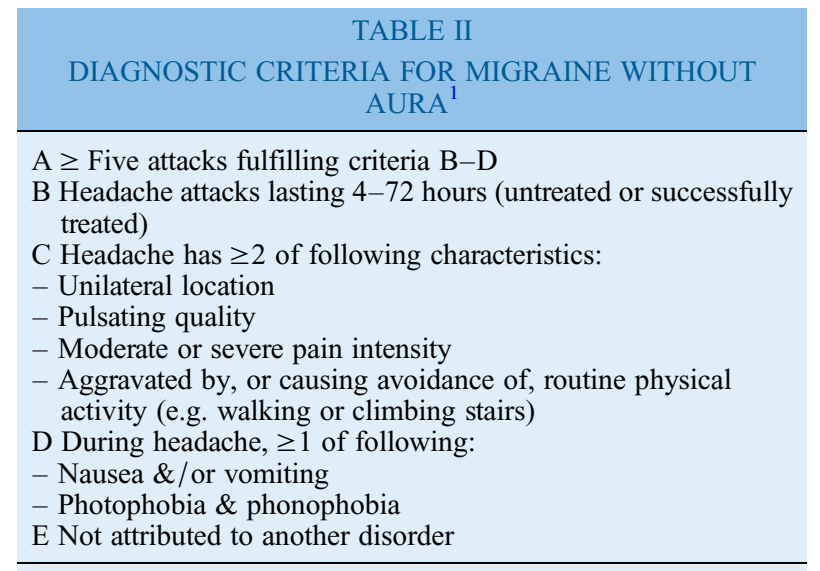

\section{Materials and methods}

A total of 240 patients who had experienced chronic mid-facial pain for at least 4 hours daily, for a minimum of 15 days per month, over a period of at least 3 months (as per the international classification of headache disorders ${ }^{1}$ ) were eligible for entry into the study. These patients were prospectively followed up for 36 months to determine their long-term outcomes.

The processes of prospective recruitment and follow up were conducted in accordance with the Consolidated Standards of Reporting Trials ('CONSORT') guidelines. ${ }^{18}$ Patients were selected by applying the International Headache Society criteria; these were used to define and differentiate tension-type pain from facial migraine without aura (Tables I and II) and from other less common types of facial neuralgia. Tension-type facial pain and facial migraine become more difficult to distinguish from each other when pain frequency increases. ${ }^{19}$ Some patients with severe exacerbation of tension-type facial pain experience a migrainous attack, suggesting an overlap between the two conditions. $^{20}$ Migraine with aura was much easier to distinguish from tension-type pain than migraine without aura.

The recruitment inclusion and exclusion criteria for entry into the cohort are listed in Table III. Only patients aged between 16 and 65 years were recruited. A standard patient history was taken, as shown in Table IV.

Basic patient data were collected from patients, including their state identity number (the unique identifier number provided by the Maltese government for every individual), age, sex, address, contact number, date seen and length of follow up in months. The main site of facial pain (unilateral, bilateral, alternating, right or left, frontal, peri-orbital, temporal, occipital or cheeks), its quality, duration and frequency was recorded. Exacerbating factors such as light, noise or exercise were noted, as was a personal history or family history of migraine.

Pregnant women, and patients with facial trauma or with pain caused by changes in ambient pressure (such
TABLE III

COHORT INCLUSION AND EXCLUSION CRITERIA

Inclusion criteria

Age 16-65 years

$>15$ pain days per month for $>3$ months

Pain affecting mid-face but may also involve head

Normal ENT examination, fundoscopy, cranial nerves \& blood pressure

Normal nasal endoscopy \& CT of sinuses \& brain

Exclusion criteria

Symptoms of sinusitis (e.g. rhinorrhoea, postnasal drip or hyposmia)

Sinus surgery within 2 years

Pregnancy

Facial pain associated with barotrauma

Facial trauma

Temporomandibular joint dysfunction \& pain of dental origin

Patients on antidepressants, hypnotics, $\beta$-blockers, clopidogrel or aspirin

$>$ One attack migraine per month

Degenerative disease (e.g. multiple sclerosis) or CNS tumours

Alcohol or substance abuse

Medication overuse headache

Sinuses CT shows mucosal thickening $>3 \mathrm{~mm}$

$\mathrm{CT}=$ computed tomography; $\mathrm{CNS}=$ central nervous system

as flying or diving), were excluded. Patients with temporomandibular dysfunction with clicking, tenderness of the temporomandibular joint or dental pain related to thermal sensitivity or percussion of the teeth were excluded.

Any symptoms that have been implicated in the diagnosis of rhinosinusitis, such as nasal obstruction, postnasal drip, rhinorrhoea, hyposmia, cough, fever, halitosis, toothache, fatigue or ear pressure, were recorded. Nasal atopy, whether intermittent or persistent, and whether supported by positive skin tests or not, was also recorded. The presence of rhinitis, or

\section{TABLE IV}

FACIAL PAIN PATIENTS: STRUCTURED CLINICAL INTERVIEW AND FOLLOW UP

Length of history

Site: peri-orbital, paranasal, cheeks, frontal, vertex, occipital, temporal-unilateral, bilateral

Quality: pressing, aching, throbbing

Duration, frequency \& intensity

Presence of photophobia, nausea or vomiting

Presence of nasal obstruction, postnasal drip, rhinorrhoea,

hyposmia, cough, fever, halitosis, toothache, ear pressure or fatigue

History of migraine, or family history of migraine

History of systemic illness (e.g. lung disease)

History of atopy \& skin test positivity

Details of past nasal surgery

Cigarette smoke exposure

Analgesic use: type, dose

BMI, education level \& occupation or income

Final diagnosis

Signs on nasal endoscopy: normal, pus, polyps, mucosal oedema

CT results: normal, rhinitis, sinusitis, anatomical abnormality

Treatment given

Treatment modified

Outcome or follow up

$\mathrm{BMI}=$ body mass index $\mathrm{CT}=$ computed tomography 
other significant respiratory or systemic disease, was recorded; this is because an association of headaches with asthma, rhinitis or chronic bronchitis has been described. ${ }^{21}$ The presence of atopy, especially if the patient had positive skin tests, was also recorded.

Exposure to tobacco smoke, whether active or passive, was recorded. A history of systemic illness such as hepatic, renal or pulmonary disease was noted.

Any prior surgical treatment was documented, and only patients whose sinus surgery pre-dated the study by two years were allowed to participate. Patients whose facial pain was accompanied by a tension headache were allowed to participate in the study. Patients with mixed tension-type pain with migraine were included in the study as long as they did not have more than one episode of migraine per month, in accordance with criteria established by previous studies on tension headache. ${ }^{22-24}$ Patients with more frequent migraine were excluded because they have been shown to have variations in blood serotonin levels. ${ }^{25}$ Such variations could affect the outcome of serotonin estimation carried out as part of this study on a selected group of patients with mid-facial pain; however, these results will not be reported in this paper.

Patients with a history of psychiatric illness or those on any antidepressant, antipsychotic or hypnotic treatment were excluded as such individuals are suspected to have dysfunctional serotonergic pathways. Indeed, headaches have been associated with depression. ${ }^{26,27}$

Individuals with medication overuse headaches were excluded because they could constitute a particular group that is difficult to treat and whose medication may have altered serotonin reuptake activity. Patients with a history of substance or alcohol abuse were excluded for the same reasons.

\section{Treatment regimes}

As all patients had chronic pain (more than 15 pain days per month), prophylactic treatment was indicated. For mid-facial pain, $10 \mathrm{mg}$ amitriptyline at night was prescribed for eight weeks. A second eight-week course was prescribed if the patient did not respond to the initial course of treatment. Patients who relapsed were continued on this medication for up to one year. Further relapses were treated with carbamazepine. Subsequent to this study, we now use pregabalin.

Prophylaxis for patients with facial migraine consisted of $10 \mathrm{mg}$ amitriptyline or $20 \mathrm{mg}$ propranolol daily for eight weeks. Triptans, being more expensive, were prescribed for breakthrough episodes or for more severe pain. Non-steroidal anti-inflammatory drugs were given as an alternative to triptans to patients not wishing to have prophylactic treatment. Cost was an important consideration because patients had to fund their own treatment.

Treatment success was defined as a greater than 50 per cent reduction in pain frequency, intensity or both, as laid out in the Cochrane guidelines. ${ }^{28}$

\section{Follow up}

Patients recruited into the cohort were followed up for three years, from June 2010 to May 2013.

Details of facial pain frequency and severity, medical treatment, any changes to treatment, and the results of follow up were recorded. The type and dose of any medication prescribed, together with outcome and addition to or change in medication, were noted. If facial pain recurred after treatment, the elapsed time between the course of treatment and recurrence was recorded. Clinical success was defined as a greater than 50 per cent decrease in pain frequency, pain intensity or both. Outcome in the cohort follow up at 36 months was broadly classified according to International Headache Society guidelines as remaining chronic, becoming episodic (1-14 days of pain per month) or having resolved.

Following the initial interview, all patients were reviewed after four weeks. Patients were then contacted for telephone interview at least once per year during follow up to ascertain the progression of facial pain. Symptomatic patients could obtain a same-day appointment at the out-patient clinic if required. Another two attempts were made to contact those who did not respond to the telephone call. Failing this, a letter was sent to their last known address in an attempt to elicit a response.

\section{Statistics}

Statistical analyses were conducted using SPSS Statistics software version 16.0 (Chicago, Illinois, USA). Results are presented as mean \pm standard deviation. Comparisons between patients with mid-facial tension-type pain and those with facial migraine were made using a chi-square test. When calculating treatment efficacy, the cut-off point between success and failure was a greater than 50 per cent improvement in pain scores. The dichotomous analysis was performed using the chi-square test. Statistical significance was set at $p<0.05$.

\section{Results}

The mean age of 240 patients with chronic facial pain was $37.7 \pm 12.4$ years. Most were women $(172$, or 72 per cent).

The great majority (156) of these patients were found to have chronic mid-facial segmental tension-type pain. Sixty-one patients had facial migraine, of which 16 had migraine with aura. Eight individuals had a combination of mid-facial pain and migraine. The remaining 15 had cranial nerve neuralgias, cluster headaches and temporal arteritis (Table V). Most of the results relate to the two main patient groups.

The BMI, level of education and occupation of these patients were compared to national statistics. The national census of 2005 recorded the Maltese population as $404962 .{ }^{29}$ Between the ages of 16 and 65 years, 49.5 per cent of the Maltese population were 


\begin{tabular}{lrc}
\multicolumn{3}{c}{ TABLE V } \\
CHRONIC FACIAL PAIN CAUSES \\
\hline Diagnosis & \multicolumn{2}{c}{ Patients } \\
\cline { 2 - 3 } & $n$ & $\%$ \\
\hline Chronic MFP & 156 & 65 \\
Facial migraine & 61 & 25.5 \\
Chronic MFP \& migraine & 8 & 3.3 \\
CN V neuralgia & 4 & 1.7 \\
Cluster headache & 3 & 1.3 \\
CN IX neuralgia & 2 & 0.8 \\
MFP \& CN V neuralgia & 2 & 0.8 \\
Temporal arteritis & 1 & 0.4 \\
Glaucoma & 1 & 0.4 \\
MFP \& cervical spondylosis & 1 & 0.4 \\
Combined CN IX \& V neuralgia & 1 & 0.4 \\
\hline
\end{tabular}

$\mathrm{MFP}=$ mid-facial pain; $\mathrm{CN}=$ cranial nerve

women, while 72 per cent of the facial pain cohort were women.

\section{Body mass index}

National statistical data collected by the Health Department National Survey of 2008 recorded the mean BMI for the Maltese adult population as $26.5 \mathrm{~kg} / \mathrm{m}^{2},{ }^{30}$ while the mean BMI for 240 patients with chronic facial pain was $25.4 \pm 4.2 \mathrm{~kg} / \mathrm{m}^{2}$.

\section{Education level}

Table VI shows the proportion of the population with a primary, secondary, higher secondary and tertiary level of education. In general, facial pain patients had a higher level of education than the general population. The fact that these patients attended a private clinic may be relevant to these findings.

\section{Occupation}

The national census of 2005 classified occupations into categories 1 to 10 . Housewives, students and pensioners were missing from the national classification as they were not considered to be gainfully employed. In this study, these groups were given the code numbers 11,12 and 13 respectively. Table VII gives the relative percentages of the different occupations in the chronic facial pain patient group, together with the national percentage for each category.

Patients with chronic facial pain consulting a private specialist were likely to be better educated and have a

\begin{tabular}{lcccc}
\multicolumn{5}{c}{ TABLE VI } \\
EDUCATION LEVEL IN GENERAL MALTESE AND STUDY \\
POPULATIONS \\
\hline Population & Primary & Secondary & $\begin{array}{c}\text { Higher } \\
\text { secondary }\end{array}$ & Tertiary \\
\hline $\begin{array}{l}\text { General } \\
\text { Maltese (\%) }\end{array}$ & 28.8 & 45.2 & 13.8 & 12.2 \\
$\begin{array}{l}\text { Current study* } \\
(\%)\end{array}$ & - & 37.2 & 29.9 & 32.9 \\
\hline${ }^{*} n=240$ & & & & \\
\end{tabular}

\begin{tabular}{|c|c|c|}
\hline $\begin{array}{r}\text { TABLE VII } \\
\text { OCCUPATION TYPE IN GENERAL } \\
\text { POPULATION }\end{array}$ & LTESE & TUDY \\
\hline Type & Populati & \\
\hline & $\begin{array}{l}\text { General } \\
\text { Maltese }\end{array}$ & Study \\
\hline Armed forces & 1 & 0 \\
\hline Legislator, senior official or manager & 9 & 8 \\
\hline Professional & 11.7 & 14.3 \\
\hline Technician or associate professional & 12.5 & 8.8 \\
\hline Clerical & 14.8 & 20.6 \\
\hline Service worker, shop \& sales worker & 16.3 & 10.5 \\
\hline Skilled agricultural or fishery worker & 1.5 & 0 \\
\hline Crafts or trade worker & 13.6 & 2.9 \\
\hline $\begin{array}{l}\text { Plant or machine operator or } \\
\text { assembler }\end{array}$ & 9.1 & 6.7 \\
\hline Elementary occupations & 10.5 & 4.7 \\
\hline Housewife & - & 18 \\
\hline Student & - & 3.4 \\
\hline Pensioner & - & 2.1 \\
\hline
\end{tabular}

better job than the general population, with a slightly lower BMI than the national average.

\section{Chronic mid-facial pain}

Of the 156 patients with chronic mid-facial tensiontype pain, 111 (71 per cent) were women, with a mean age of $37 \pm 11.6$ years (Table VIII). The 45 men were slightly older, with a mean age of $40 \pm 14$ years. The mean age of all mid-facial pain patients was $37.8 \pm 12.4$ years. Dizziness was a common accompanying symptom to facial pain, occurring in 37 out of 156 (23.7 per cent) patients and usually resolving within a week of commencing treatment.

Patients with mid-facial pain were treated with an 8week course of $10 \mathrm{mg}$ amitriptyline per day and followed up for 36 months. If there was no response after two weeks, the dose was increased to $20 \mathrm{mg}$, but this was unusual. In 24 out of 156 patients (15.3 per cent), pain recurred within 3 months. Even when the pain was not as severe as it had previously been, these individuals were offered a second course of amitriptyline.

Patients who retained their pre-treatment pattern of pain were classified as having 'chronic' pain. In patients whose pain decreased in frequency and severity so that they recorded less than one pain day a month, the pain was considered to be 'resolved'. Patients with 1-14 pain days per month at 36 months were labelled as having 'episodic' pain.

Facial pain resolved in almost half of the mid-facial pain patients ( 45.5 per cent), while in a third it changed to an episodic pattern ( 37.2 per cent) with infrequent bouts of pain (Table IX). In 14 patients (9 per cent), chronic pain was retained, that is, they had more than 15 pain days per month. The remaining 8.3 per cent were lost to follow up.

For those patients in the episodic and chronic groups whose pain returned, it did so after $10.5 \pm 10$ months following their course of amitriptyline. 
TABLE VIII

DEMOGRAPHIC DATA FOR MID-FACIAL PAIN AND FACIAL MIGRAINE PATIENTS

\begin{tabular}{lrrrr}
\hline \multirow{2}{*}{ Group } & \multicolumn{2}{c}{ Patients $(n(\%))$} & & \multicolumn{2}{c}{ Age (mean \pm SD, years) } \\
\cline { 2 - 3 } \cline { 5 - 6 } & Men & Women & Men & Women \\
\hline MFP* & $45(29)$ & $111(71)$ & $40 \pm 14.0$ & $37 \pm 11.6$ \\
Facial migraine $\dagger$ & $20(33)$ & $41(67)$ & $38.5 \pm 10.9$ & $35 \pm 10.9$ \\
\hline
\end{tabular}

${ }^{*} n=156 ;{ }^{\dagger} n=61 . \mathrm{SD}=$ standard deviation; MFP $=$ mid-facial pain

\section{Facial migraine}

A total of 61 patients had facial migraine: 41 (67.2 per cent) were women (mean age $35 \pm 10.9$ years) and 20 were men (mean age $38.5 \pm 10.9$ years) (Table VIII). The mean age of all facial migraine patients was $36.1 \pm 10.9$ years. Dizziness was described in only four (6.5 per cent) facial migraine patients.

Patients were treated prophylactically with $10 \mathrm{mg}$ amitriptyline daily for eight weeks $(n=16)$ or propranolol $20 \mathrm{mg}$ daily for eight weeks $(n=21)$. One patient was treated with both. Patients who did not accept prophylactic treatment received triptans (sumatriptan or zolmitriptan, $n=8$ ) or non-steroidal anti-inflammatory drugs $(n=13)$ on an 'as required' basis. One took paracetamol with codeine and one did not receive any treatment. The choice of treatment was influenced by patient preference and cost.

Patients were followed up for 36 months. On evaluation at 36 months, the largest proportion of facial migraine patients (41 per cent) had unchanged chronic symptoms. In 23 per cent, their pain had 'resolved' to less than one episode per month. In onethird, the pain frequency was reduced to 'episodic', i.e. occurring between 1 and 14 days per month (Table IX). Overall, in patients whose facial migraine did not resolve ('chronic' and 'episodic' groups together), the original pain pattern took a mean of $8.7 \pm 10$ months to return after treatment. In 18 patients (30 per cent), pain returned within 3 months of stopping treatment.

In the subgroup of patients receiving prophylactic propranolol $(n=21)$, the previous pain pattern returned after $13.3 \pm 12.3$ months; in those receiving prophylactic amitriptyline $(n=16)$, pain returned after $18.4 \pm$ 16.1 months; and in patients receiving triptans $(n=8)$, the previous pain pattern returned after $19.3 \pm 17.9$ months. The shortest interval before return to the previous pain pattern was seen in patients receiving

TABLE IX
$\begin{array}{llllc}\text { OUTCOME IN MID-FACIAL PAIN AND FACIAL MIGRAINE } \\
\text { PATIENTS* }\end{array}$
\begin{tabular}{llllc}
\hline Group & Resolved & Episodic & Chronic & Lost \\
\hline MFP $^{\dagger}$ & $71(45.5)$ & $58(37.2)$ & $14(9)$ & $13(8.3)$ \\
Facial migraine $^{\ddagger}$ & $14(23)$ & $15(24.5)$ & $25(41)$ & $7(11.5)$ \\
\hline Data represent patient numbers and percentages. $^{*}$ At & 36 -month \\
follow up. ${ }^{\dagger} n=156 ;{ }^{\ddagger} n=61$. MFP = mid-facial pain
\end{tabular}

non-steroidal anti-inflammatory drugs 'as required' $(n=13)$ : their pain returned after $9.7 \pm 13.3$ months.

\section{Mid-facial pain versus facial migraine}

A comparison of outcomes revealed that patients with mid-facial pain and facial migraine had similar dropout rates on follow up (chi-square test, $p=0.69$ (not significant)), and similar rates of progression from chronic to episodic pain (chi-square test, $p=$ 0.27 (not significant)). However, mid-facial pain patients were much more likely to experience resolution of their pain compared to patients with migraine $(p=0.05)$, and facial migraine was significantly more likely to remain chronic $(p=0.00001)$.

The most common sites of pain described by patients with mid-facial pain were the nasion and frontal regions; most had a combination of sites, with 384 sites described by 156 patients. In facial migraine, 141 sites were described by 61 patients, with the peri-orbital and frontal regions being most commonly involved (Table $\mathrm{X}$ ). In mid-facial pain, the pain was typically bilateral; in migraine, it was bilateral in half of patients (26, or 48 per cent), and unilateral or alternating in the other half.

In mid-facial pain, the pain was characteristically pressing in 122 patients ( 78 per cent) and aching in 30 patients (19 per cent). In facial migraine, the pain was described as throbbing in 34 patients ( 56 per cent), as pressing in 17 (28 per cent), and as aching, stabbing, boring, pinching or sharp in the rest. Thus, the description of pain in mid-facial pain was more uniform.

Photophobia and nausea were much more common in facial migraine (Table XI). Most facial migraine patients had never been properly diagnosed and had a low awareness of this condition. As a consequence, they typically denied a history of migraine and attributed their previous symptoms to sinusitis. However, when asked about migraine in their families, the rates turned out to be high.

The incidence of rhinitis, and rates of positive skin tests, exposure to cigarette smoke or systemic illness such as asthma were similar in the mid-facial pain and facial migraine groups (Table XII).

\section{Mid-facial pain and facial migraine}

In 8 patients with a combination of mid-facial pain and migraine, the pain pattern reappeared after a mean of $12.6 \pm 4.5$ months after treatment with amitriptyline. 


\begin{tabular}{|c|c|c|c|c|c|c|}
\hline \multicolumn{7}{|c|}{ TABLE X } \\
\hline Group & Frontal & Nasion & Peri-orbital & Cheeks & Temporal & Occipital \\
\hline $\mathrm{MFP}^{\dagger}$ & $109(70)$ & $97(62)$ & $72(46)$ & 49 (31) & $27(17)$ & $30(19)$ \\
\hline Facial migraine & $32(52)$ & $22(36)$ & $31(51)$ & $17(28)$ & 27 (44) & $12(20)$ \\
\hline
\end{tabular}

Data represent patient numbers and percentages. ${ }^{*}$ Patients generally had more than one site involved at the same time. ${ }^{\dagger} n=156 ;{ }^{\ddagger} n=61$. MFP = mid-facial pain

\section{Neuralgia and cluster headache}

Most patients with trigeminal or glossopharyngeal neuralgia responded well to carbamazepine, while those with cluster headaches responded to triptans or prophylactic low-dose propranolol.

\section{Discussion}

This cohort represents a sample of patients who either self-referred or were referred by their general practitioner to a community-based otolaryngologist, and may therefore not be representative of patients in the whole population with chronic facial pain. It is also likely that a broader spectrum of pain types would be encountered in an otolaryngological practice than in a tertiary referral neurological centre. The age and gender distribution in patients with facial pain in Malta was very similar to that in a group of 409 patients with facial pain presenting to a rhinology clinic in the UK, where the mean age was 37.6 years and 68.6 per cent were female. ${ }^{31}$

The patients in this cohort had a similar mean BMI to that of the general population, but were better educated. The fact that the patients attended a private practice may be relevant to these findings. In previous studies, patients with chronic tension headache were low academic achievers ${ }^{32}$ and had lower incomes ${ }^{33}$ than the general population. In men, tension-type headaches were associated with sedentary occupations. ${ }^{34}$

Patient dropout rates varied between 8 and 11 per cent. Most tension-type pain was described as of mild-to-moderate intensity; therefore, not all patients may have thought it worth the time and effort to attend follow up. Most individuals were already taking analgesics on an 'as required' basis and there was some resistance to changing to prophylactic

\section{TABLE XI}

ADDITIONAL MEDICAL HISTORY AND SYMPTOMS FOR MID-FACIAL PAIN AND FACIAL MIGRAINE PATIENTS

\begin{tabular}{|c|c|c|c|c|}
\hline \multirow[t]{2}{*}{ Group } & \multicolumn{2}{|c|}{$\begin{array}{l}\text { History of } \\
\text { migraine }\end{array}$} & \multirow[t]{2}{*}{ Photophobia } & \multirow[t]{2}{*}{$\begin{array}{l}\text { Nausea \&/or } \\
\text { vomiting }\end{array}$} \\
\hline & Self & Family & & \\
\hline MFP* & $35(22)$ & $39(25)$ & 45 (29) & $42(27)$ \\
\hline $\begin{array}{l}\text { Facial } \\
\text { migraine }^{\dagger}\end{array}$ & 9 (15) & $37(61)$ & $45(74)$ & $31(51)$ \\
\hline
\end{tabular}

Data represent patient numbers and percentages. ${ }^{*} n=156 ;{ }^{\dagger} n=$ 61. MFP = mid-facial pain treatment. Therefore, patient education was important to explain the aetiology of their condition. It was encouraging that in patients with mid-facial pain, pain frequency or severity significantly dropped within two weeks of starting low-dose amitriptyline. ${ }^{35}$

A 10-year follow-up study of 62 Danish patients with chronic tension-type headache showed that 45 per cent went into remission. A reduction in headache frequency led to the development of an episodic pattern from a chronic pattern of headaches. ${ }^{36}$

The same findings were reported in another Danish study of 740 individuals with headache followed up for 2 years. ${ }^{37}$ Similar data were also recorded in the USA. $^{38}$ However, patients with coexisting chronic tension-type headache and migraine were more likely to continue having frequent headaches. Similar observations for facial pain were recorded in this study (Table IX). Clinical improvement ('resolved' and 'episodic' outcomes taken together) was much higher in mid-facial pain patients ( 82.7 per cent) than in facial migraine patients (51 per cent).

The treatment of mid-facial pain patients was uniform and the outcome more favourable. Facial migraine patients treated with non-steroidal antiinflammatory drugs 'as required' were quick to return to their previous pain pattern, while prophylactic lowdose amitriptyline or triptans seemed to break the pain cycle and give longer-lasting relief.

Because time to recurrence of the original pain pattern was, in general, similar in both mid-facial pain and facial migraine patients, a common underlying cause of these conditions is hypothesised. Medication may simply reduce the sensitivity of the nociceptive pathway for a variable period of time, probably at the

\begin{tabular}{|c|c|c|c|c|}
\hline \multicolumn{5}{|c|}{$\begin{array}{c}\text { TABLE XII } \\
\text { RHINITIS, POSITIVE SKIN TESTS, SMOKE EXPOSURE } \\
\text { AND SYSTEMIC ILLNESS IN MID-FACIAL PAIN AND } \\
\text { FACIAL MIGRAINE PATIENTS }\end{array}$} \\
\hline Group & Rhinitis & $\begin{array}{l}\text { Positive skin } \\
\text { test }\end{array}$ & $\begin{array}{l}\text { Smoke } \\
\text { exp }\end{array}$ & $\begin{array}{c}\text { Syst } \\
\text { illness* }\end{array}$ \\
\hline $\mathrm{MFP}^{\dagger}$ & $35(22)$ & $8(5)$ & $22(14)$ & $6(4)$ \\
\hline $\begin{array}{l}\text { Facial } \\
\text { migraine }\end{array}$ & $10(16)$ & 1 (2) & 10 (16) & 1 (2) \\
\hline
\end{tabular}

Data represent patient numbers and percentages. * For example, asthma. ${ }^{\dagger} n=156 ;{ }^{\ddagger} n=61$. Exp $=$ exposure; syst $=$ systemic; MFP $=$ mid-facial pain 
level of the synaptic relay in the trigeminal subnucleus caudalis.

- In a cohort of chronic facial pain patients, 72 per cent were women in their fourth decade

- Patients had a slightly lower mean body mass index, and better educations and jobs, than the general population

- Commonest causes of pain were tension-type mid-facial pain and facial migraine

- Patients with tension-type mid-facial pain responded to low-dose amitriptyline

- Patients with facial migraine responded to low-dose amitriptyline and triptans

The pain resolved in nearly half of the individuals with mid-facial pain, and in a third it became episodic. We do not know whether the medication altered the natural course of the condition as no long-term study of untreated patients with this condition has been performed. However, these findings are similar to those obtained for tension-type headache patients. ${ }^{39}$

Photophobia has been reported in 49-95 per cent of patients with migraine. ${ }^{40,41}$ In this series, the incidence was 74 per cent in facial migraine patients, which is consistent with the other studies (Table XI).

Nausea has been reported as present in 90 per cent of patients with migraine, with vomiting present in 50 per cent. ${ }^{40,41}$ The rates of these symptoms in facial migraine patients in this study were similar (Table XI).

The rates of rhinitis, positive skin test results, cigarette smoke exposure or systemic illness such as asthma were similar in the mid-facial pain and facial migraine groups, and did not differ from those in the general Maltese population. ${ }^{42}$ This contrasts with findings from a Norwegian study, which showed an association of asthma, rhinitis and chronic bronchitis with migrainous and non-migrainous headaches. ${ }^{21}$

Education is important to encourage patients to keep analgesic doses as low as possible. This will help to prevent the development of medication overuse headaches, especially those resulting from migraine medication overuse. ${ }^{43}$

During the three years follow up, two of the patients became pregnant; their facial pain significantly improved during pregnancy. In one female patient with facial migraine, thyroid nodules were incidentally discovered and she was eventually diagnosed with medullary carcinoma of the thyroid.

\section{Conclusion}

In this cohort of patients with chronic facial pain, 72 per cent were women in their fourth decade of life. As a group, the cohort had a slightly lower than average BMI, better educational attainment and better jobs compared with the general population.
The commonest causes of pain were tension-type mid-facial pain and facial migraine. Patients in the first group frequently responded to an 8-week course of low-dose amitriptyline, with nearly half of the patients being pain free at 36 months and onethird suffering less severe and less frequent episodes of pain. For patients with facial migraine, the most effective long-term treatment was low-dose amitriptyline and triptans.

\section{Acknowledgements}

This work was partly funded by the Malta Government Scholarship Scheme and the dean's fund from the Faculty of Medicine and Surgery, University of Malta. Dr Neville Calleja, the Head of Department of Medical Statistics, Department of Health, Malta, kindly assisted with the clinical analyses. The authors are especially grateful to all patients who kindly consented to taking part in this study.

\section{References}

1 Headache Classification Committee of the International Headache Society. The International Classification of Headache Disorders: 2nd edition. Cephalalgia 2004;24(suppl 1):9-160

2 Agius AM. Chronic sinusitis in Malta - correlation between symptoms and CT scan. Rhinology 2010;48:59-64

3 Kieff DA, Busaba NY. Negative predictive value of normal nasal endoscopy for sinus disease as a cause of isolated facial pain. J Laryngol Otol 2011;125:1038-41

4 Fokkens WJ, Lund VJ, Mullol J, Bachert C, Cohen N, Cobo R et al. European position paper on rhinosinusitis and nasal polyps 2007. Rhinology 2007;45(suppl 20):1-139

5 Fokkens WJ, Lund VJ, Mullol J, Bachert C, Alobid I, Baroody F et al. European position paper on rhinosinusitis and nasal polyps 2012. Rhinology 2012;50(suppl 23):1-298

6 West B, Jones NS. Endoscopy-negative, computed tomographynegative facial pain in a nasal clinic. Laryngoscope 2001;111: $581-6$

7 Jones NS. Midfacial segmental pain: implications for rhinitis and sinusitis. Curr Allergy Asthma Rep 2004;4:187-92

8 Jones NS. Midfacial segment pain: implications for rhinitis and rhinosinusitis. Clin Allergy Immunol 2007;19:323-33

9 Bendtsen L. Sensitisation: its role in primary headache. Curr Opin Investig Drugs 2001;3:449-53

10 Sessle BJ, Hu JW, Amano N, Zhong G. Convergence of cutaneous, tooth pulp, visceral, neck and muscle afferents onto nociceptive and non-nociceptive neurons in trigeminal subnucleus caudalis (medullary dorsal horn) and its implications for referred pain. Pain 1986;27:219-35

11 Bartsch T, Goadsby PJ. Increased responses in trigeminocervical nociceptive neurons to cervical input after stimulation of the dura mater. Brain 2003;126:1801-13

12 Bendtsen L, Jensen R, Olesen J. A non-selective (amitriptyline) but not a selective (citalopram) serotonin reuptake inhibitor is effective in the prophylactic treatment of chronic tension-type headache. J Neurol Neurosurg Psychiatry 1996;61:285-90

13 O'Brien B, Goeree R, Steiner D. Prevalence of migraine headache in Canada: a population-based survey. Int $J$ Epidemiol 1994;23:1020-6

14 Lipton RB, Scher AI, Kolodner K, Liberman J, Steiner TJ, Stewart WF. Migraine in the United States: epidemiology and patterns of health care use. Neurology 2002;58:885-94

15 Lyngberg AC, Rasmussen BK, Jorgensen T, Jensen R. Prognosis of migraine and tension-type headache: a population-based follow-up study. Neurology 2005;65:580-5

16 Eross E, Dodick D, Eross M. The Sinus, Allergy and Migraine Study(SAMS). Headache 2007;47:213-24

17 Obermann M, Mueller D, Yoon MS, Pageler L, Diener H, Katsarava Z. Migraine with isolated facial pain: a diagnostic challenge. Cephalalgia 2007;27:1278-82

18 Moher D, Hopewell S, Schulz KF, Montori V, Gøtzsche PC, Devereaux PJ et al. CONSORT 2010 explanation and elaboration: updated guidelines for reporting parallel group randomised trials. $B M J$ 2010;340:c869 
19 Silberstein SD, Lipton RB, Solomon S, Mathew NT. Classification of daily and near-daily headaches: proposed revision to IHS criteria. Headache 1994;34:1-7

20 Solomon S, Lipton RB, Newman LC. Clinical features of chronic daily headache. Headache 1992;32:325-9

21 Aamodt AH, Stovner LJ, Langammer A, Hagen K, Zwart JA. Is headache related to asthma, hay fever and chronic bronchitis? The Head-HUNT Study. Headache 2007;47:204-12

22 Jensen R, Hindberg I. Plasma serotonin increase during episodes of tension-type headache. Cephalalgia 1994;14:219-22

23 Bendtsen L, Jensen R, Hindberg I, Gammeltoft S, Olesen J. Serotonin metabolism in chronic tension-type headache. Cephalalgia 1997;17:843-8

24 Bendtsen L, Mellerup ET. The platelet serotonin transport in primary headaches. Eur J Neurol 1998;5:277-82

25 Ribeiro CAF, Cotrim MD, Morgadinho MT, Ramos MI, Santos ES, de Macedo Tdos R. Migraine, serum serotonin and platelet 5-HT2 receptors. Cephalalgia 1990;10:213-19

26 Delgado PL. Serotonin noradrenaline reuptake inhibitors: new hope for the treatment of chronic pain. Int J Psychiatry Clin Pract 2006;10:16-21

27 Yucel B, Kora K, Ozyalcin S, Alçalar N, Ozdemir O, Yücel A. Depression, automatic thoughts, alexithymia and assertiveness in patients with tension-type headache. Headache 2002;42: 194-9

28 Saarto T, Wiffen PJ. Antidepressants for neuropathic pain. Cochrane Database Syst Rev 2007;(4):CD005454

29 Census of Population and Housing 2005, National Statistics Office, Malta. In: http://www.nso.gov.mt [25 March 2014]

30 European Health Interview Survey: Lifestyle Report, Department of Health Information, Ministry for Health, Malta, 2008. In: www.healthsurveys.gov.mt [25 March 2014]

31 Daudia AT, Jones NS. Facial migraine in a rhinological setting. Clin Otolaryngol 2002;27:521-5

32 Boardman HF, Thomas E, Croft PR, Millson DS. Epidemiology of headache in an English district. Cephalalgia 2003;23:129-37

33 Schwartz BS, Stewart WF, Simon D, Lipton RB. Epidemiology of tension-type headache. JAMA 1998:279:381-3

34 Rasmussen BK. Migraine and tension-type headache in a general population: precipitating factors, female hormones, sleep pattern and relation to lifestyle. Pain 1993;53:65-72
35 Agius AM, Jones NS, Muscat R. A randomised controlled trial comparing the efficacy of low-dose amitriptyline, amitriptyline with pindolol and placebo in the treatment of chronic tensiontype facial pain. Rhinology 2013;50:143-53

36 Lyngberg AC, Rasmussen BK, Jorgensen T, Jensen R. Has the prevalence of migraine and tension-type headache changed over a 12-year period? A Danish population survey. Eur J Epidemiol 2005;20:243-9

37 Lyngberg AC, Rasmussen BK, Jorgensen T, Jensen R. Prognosis of migraine and tension-type headache: a population-based follow-up study. Neurology 2005;65:580-5

38 Spierings EL, Mutsaerts WK. Course of frequent/daily headache in the general population and in medical practice. Rev Neurol Dis 2010;7:103-10

39 Lance JW, Anthony M. Some clinical aspects of migraine. Arch Neurol 1966;15:356-61

40 Rasmussen BK, Olesen J. Migraine with aura and migraine without aura: an epidemiological study. Cephalalgia 1992;12: 221-8

41 Olesen J. Some clinical features of the acute migraine attack. An analysis of 750 patients. Headache 1978;18:268-71

42 Agius AM, Cordina M, Calleja N. The role of atopy in Maltese patients with chronic rhinitis. Clin Otolaryngol 2004;29:1-7

43 Bendtsen L, Birk S, Kasch H, Aegidius K, Sørensen PS, Thomsen LL et al. Reference programme: diagnosis and treatment of headache disorders and facial pain. Danish Headache Society, 2nd Edition, 2012. J Headache Pain 2012;13(suppl 1): S1-29

Address for correspondence:

Dr A M Agius,

St Anne's Clinic

Triq Kanonku Karmenu Pirotta,

B'Kara BKR1111, Malta

E-mail: aagius@synapse.net.mt

Dr A M Agius takes responsibility for the integrity of the content of the paper

Competing interests: None declared 